\title{
ESCHERICHIA COLI FROM HORSES REARED IN AND AROUND BANGLADESH AGRICULTURAL UNIVERSITY CAMPUS- A STUDY ON ISOLATION AND CHARACTERIZATION
}

\author{
K. M. Nahar, M. S. R. Khan, M. Alam ${ }^{1}$ and M. K. Nesa \\ Department of Microbiology and Hygiene, Bangladesh Agricultural University, \\ Mymensingh-2202, Bangladesh
}

\begin{abstract}
The present study was conducted with a view to isolate and characterize Escherichia coli (E. coli) from horses reared in and around Bangladesh Agricultural University (BAU) campus and to know the clonal relationship of the isolates with $E$. coli of cattle, goat and chicken. It also focused on the determination of antimicrobial sensitivity and resistant pattern of the isolated horse E. coli. A total of 10 faecal samples, comprising 4 from diarrhoeic horses and 6 from apparently healthy horses were collected. The overall prevalence of $E$. coli was recorded as $60 \%$. All isolates fermented dextrose, maltose, sucrose, lactose and mannitol with the production of both acid and gas. The isolates were positive to MR and Indole tests, but negative to VP test. DNA fingerprinting analysis using PFGE of Xbaldigested genomic DNA revealed that the strains of E. coli from different areas seem to be same clonal lineage, although no genetic clue could be found related to cattle, goat and chicken E. coli strains. The antimicrobial sensitivity and resistance pattern showed that the isolates of horse $E$. coli were highly sensitive to ciprofloxacin and chloramphenicol but to the amoxicillin and cephalexin, the isolates were highly resistant
\end{abstract}

Key Words: E. coli, Horse, Isolation, Characterization

\section{INTRODUCTION}

E. coli is a Gram-negative, rod shaped, motile, capsulated, flagellated and non-spore forming facultative anaerobes under the family Enterobacteriaceae. Some E. coli strains can cause clinical symptoms in humans and animals, among which enteritis is common. $E$. coli infection is a problem in horse rearing industries and it causes septicemia, enteric infections, chronic arthritis, lethargy, depression, anorexia and sudden death. Endotoxemia, septicemia and enteric infections are the most severe problems affecting neonatal foals, often culminating in death (Hung et al., 2006). Approximately 25 percent of all septicemias in foals are caused by E. coli. Invasive strains of these bacteria enter the foal's bloodstream either through the intestinal tract, the respiratory tract, or the umbilical cord. Bacteria begin to circulate throughout the body and releases toxins. Septicemia in

\footnotetext{
1 International Centre for Diarrhoeal Disease Research, Bangladesh (ICDDRB), Dhaka, Bangladesh Corresponding author: E-mail: raisagfin@yahoo.com; Cell: +880-10721-310621
} 
foals often results in chronic arthritis, since the bacteria tend to take refuge in the joint cavities where they are difficult to reach with antibiotics. Foals with E. coli infection may also show diarrhea. The most common factor predisposing foals to developing E. coli septicemia is hypogammaglobulinemia, i.e., inadequate levels of passive antibody protection from the mare's colostrums. This is caused by several factors like inadequate nursing, poor quality colostrums in the mare, loss of colostrums prior to foaling, etc. Since a foal is often not recognized as being hypogammaglobulinemic until it becomes sick, treatment is often ineffective.

There is randomly use of antibiotic for the treatment of diarrhoeal diseases in Bangladesh. Multi-drug resistant E. coli are continuously increasing due to indiscriminate use of antibiotics in Bangladesh (Hussain et al., 1982 and Kabir, 2010). Incomplete course of treatment of diarrhea or urinary tract infection might have influenced to produce a new generation of virulent and resistant type of E. coli (Kaura et al., 1988; Marshall et al., 1990). Bacterial resistance to antibiotics is mainly due to the presence of plasmid and chromosomal DNA, which contains resistance factor. Thus, bacteria become more and more resistant to antibiotics and new generation of antibiotics becomes necessary. Different parameters including the isolation, identification, vaccination, plasmid profiling, antibiotic sensitivity and epidemiological investigation of $E$. coli of different species have been studied in Bangladesh. However, E. coli isolation from horse and their clonal relation with other E. coli strain of cattle, goat, and chickens by pulsed field gel electrophoresis (PFGE) with specific objectives are yet to be in the context of Bangladesh. Considering this fact, the present research work was undertaken with the objectives of (i) to isolate and identify E. coli from horse, (ii) to characterize the isolated E. coli using cultural, biochemical, and molecular techniques and (iii) to study the antibacterial sensitivity of the isolated E. coli.

\section{MATERIALS AND METHODS}

The study was conducted in the Department of Microbiology and Hygiene, Bangladesh Agricultural University (BAU), Mymensingh and Enteric Microbiology Laboratory, International Centre for Diarrhoeal Disease Research, Bangladesh (ICDDR,B), Dhaka during the period of May 2009 to May 2010. Diarrhoeic horses and apparently healthy horses were selected for the experimental study. A total number of 10 field samples comprising rectal swabs were aseptically collected into nutrient broth (NB) from BAU campus, i.e., BAU Sheep \& Goat Farm (BAUSGF) and BAU Veterinary Clinic (BAUVC) and around the campus, i.e., Boyra Union Parishad (BUP). Then the samples were carried to the laboratory for the characterization of $E$. coli. Out of 10 samples 4 were collected from diarrhoeic horses and 6 were from apparently healthy horses. Nutrient broth (NB) was used to grow the E. coil organisms from the collected samples before performing hanging drop slide test and biochemical test. Nutrient agar (NA) Blood agar (BA) media were used to grow the E. coli organisms from the collected samples. Eosin methylene blue agar (EMBA) medium was used as a selective medium for the identification of E. coli organisms and antibiotic sensitivity study. McConkey agar (MCA) medium was used for enhancing 
the growth of the organisms under the family Enterobacteriaceae and characteristic colonies were produced which helps in differentiating lactose fermenting organisms from lactose non fermenting organisms (Cheesbrough, 1984). Salmonella-Shigella agar (SSA) and Brilliant green agar (BGA) were also used for the differential growth of the organisms.

In order to identify E. coli, sugar media (dextrose, maltose, lactose, mannitol and sucrose) were used for biochemical tests. Chemicals and reagents used for conducting the biochemical tests were Gram's stain, Methyl red solution, Methyl-Red Voges- Proskaure (MR-VP) broth, Kovac's reagent, Alpha-nepthanol solution, Potassium hydroxide solution, Phosphate buffered saline (PBS) solution, Phenol red, 20\% glycerine, liquid paraffin, wax, alcohol and spirit. Antibiotic sensitivity test was performed using disc diffusion or KirbyBauer test method (Bauer et al. 1996). Nine different antimicrobial discs with their concentration were used for the test. The antimicrobial agents were tetracycline, streptomycin, amoxicillin, chloramphenicol, cephalexin, ciprofloxacin, gentamicin, trimethoprim and cephradine with concentration of 30, 10, 10, 30, 30, 5, 120, 5 and $30 \mu \mathrm{g}$. The isolated E. coli of horse and previously isolated E. coli of cattle, goat and chicken were preserved in $20 \%$ glycerine. Then the isolated E. coli were inoculated into EMBA and kept at $37^{\circ} \mathrm{C}$ for overnight incubation. The organisms on EMBA produced greenish colonies with metallic sheen. Then the isolated E. coli on EMBA were placed in icebox and transported to the Enteric Microbiology Laboratory of ICDDR,B for molecular characterization by Pulsed-Field Gel Electrophoresis (PFGE). PFGE involves embedding organism in agarose, lysing the organism in situ and digesting the chromosomal DNA with restriction endonucleases that cleave infrequently. The DNA restriction patterns of the isolates are compared with one another to determine their relatedness.

\section{RESULTS AND DISCUSSION}

NB inoculated separately with the swab samples revealed the growth of bacteria after 24 hours of incubation at $37^{\circ} \mathrm{C}$ aerobically and was indicated by the presence of turbidity. In the same way, separately streaked NA plates revealed the growth of bacteria and was indicated by the growth of circular smooth, opaque, colorless colonies. BA was discolored around the growth of the organism and there was hemolysis. The organisms of the faecal samples produced slight pinkish colony and those produced green colonies were tentatively chosen to be E. coli. E. coli was presumptively selected and tentatively confirmed by bright pink colored colonies on MCA and greenish colonies with metallic sheen on EMBA produced by the organisms after overnight incubation. In Gram's staining under microscope the organism revealed Gram-negative, pink color, small rod shaped arranged as single or paired. All the isolates were found to be motile in hanging drop slide (Table 1).

Presumptively selected 2 to $3 \mathrm{~mm}$ colonies were repeatedly streaked on EMBA to check and confirm their purity. A series of biochemical tests were performed with the culture positive and Gram-negative rod shaped cells. All the isolates fermented five basic sugars (dextrose, sucrose, lactose, maltose and mannitol) produced acid and gas. Acid production 
was indicated by the color change from reddish to yellow and the gas production was noted by the appearance of gas bubbles in the inverted Durham's tubes. All the isolates were catalase positive, MR positive, VP test negative and Indole test positive. Isolates giving such pattern of biochemical reactions were regarded as E. coli (Table 2).

Table 1. Cultural, morphological and motility characteristics of the isolated E. coli

\begin{tabular}{|c|c|c|c|c|c|c|c|}
\hline \multirow{2}{*}{$\begin{array}{l}\text { Sources of } \\
\text { isolates }\end{array}$} & \multicolumn{5}{|c|}{ Colony characteristics } & \multirow{2}{*}{$\begin{array}{l}\text { Staining } \\
\text { character }\end{array}$} & \multirow[t]{2}{*}{ Motility } \\
\hline & EMBA & MCA & BGA & SSA & BA & & \\
\hline BAUSGF & $\begin{array}{l}\text { Greenish black } \\
\text { colony with } \\
\text { metallic sheen }\end{array}$ & $\begin{array}{l}\text { Bright pink } \\
\text { color smooth } \\
\text { transparent } \\
\text { raised colonies }\end{array}$ & $\begin{array}{l}\text { Green } \\
\text { color } \\
\text { colony }\end{array}$ & $\begin{array}{l}\text { Slight } \\
\text { pinkish } \\
\text { smooth } \\
\text { colonies }\end{array}$ & $\begin{array}{l}\text { Colorless } \\
\text { colony with } \\
\text { hemolysis }\end{array}$ & $\begin{array}{l}\text { Pink short } \\
\text { rod, Gram } \\
\text { negative } \\
\text { bacilli }\end{array}$ & + \\
\hline BAUVC & do & do & do & do & do & do & + \\
\hline BUP & do & do & do & do & do & do & + \\
\hline
\end{tabular}

Legend: + = positive

Table 2. Biochemical characteristics of E. coli

\begin{tabular}{lc}
\hline \multicolumn{1}{c|}{ Different Biochemical tests } & Result \\
\hline Fermentation reaction with five basic sugars: & + \\
Dextrose & + \\
Sucrose & + \\
Fructose & + \\
Maltose & + \\
Mannitol & \\
\hline Fermentation reaction with dulcitol: & + \\
Indole & + \\
MR & - \\
VP &
\end{tabular}

Legend: $+=$ positive, $-=$ negative

Out of 4 and 6 faecal samples of diarrhoeic and apparently healthy horses respectively, 3 samples each were found to be positive for E. coli infection. So, the rate of infection was greater in diarrhoeic horses compared to that of apparently healthy ones and the overall prevalence was recorded as $60 \%$ (Table 3 ).

PFGE analysis of the Xbal digested chromosomal DNA of the E. coli strains yielded 16 to 23 reproducible DNA fragments ranging in size approximately from $<20$ to $<668.9 \mathrm{Kbp}$ (Fig. 1). The fingerprint pattern in the gel was analyzed using computer software package (Quantity One Version 3.0) and after background subtraction and gel normalization, the 
fingerprint patterns were subjected to cluster analysis using the Unweighted Pair Group Method with Arithmetic Mean (UPGMA). The enzyme (XbaI) restriction digestion restricted chromosomal genome into 14-23 fragments. For cluster analysis, only fragments having a molecular weight of $30 \mathrm{~kb}$ and above were considered. PFGE analysis revealed that, the strains isolated from the horse from different areas displayed more or less similar restriction fingerprint pattern while the strains of horse, cattle, goat and chicken E. coli yielded diverse and heterogeneous banding pattern (Table 4, Fig. 1). Thus, major differences in band patterns were observed among the strains of different species.

Table 3. Prevalence of E. coli in diarrhoeic and apparently healthy horses

\begin{tabular}{|c|c|c|c|c|c|c|c|}
\hline \multirow{2}{*}{$\begin{array}{l}\text { Sources of } \\
\text { samples }\end{array}$} & \multirow{2}{*}{$\begin{array}{l}\text { Samples } \\
\text { examined } \\
\text { (no.) }\end{array}$} & \multicolumn{2}{|c|}{ Culture Examination } & \multicolumn{2}{|c|}{ Biochemical Examination } & \multicolumn{2}{|c|}{ Prevalence } \\
\hline & & $\begin{array}{c}\text { Positive for } \\
\text { E. coli }\end{array}$ & $\begin{array}{c}\text { Negative for } \\
\text { E. coli }\end{array}$ & $\begin{array}{c}\text { Positive for } \\
\text { E. coli }\end{array}$ & $\begin{array}{c}\text { Negative for } \\
\text { E. coli }\end{array}$ & $\begin{array}{l}\text { Sample } \\
\text { (no.) }\end{array}$ & $\%$ \\
\hline $\begin{array}{l}\text { Diarrhoeic } \\
\text { horses }\end{array}$ & 4 & 3 & 1 & 3 & 1 & 3 & 75 \\
\hline $\begin{array}{l}\text { Apparently } \\
\text { healthy horses }\end{array}$ & 6 & 3 & 3 & 3 & 3 & 3 & 50 \\
\hline Total & 10 & 6 & 4 & 6 & 4 & 6 & 60 \\
\hline
\end{tabular}

Table 4. Approximate number of band of E. coli from horse, cattle, goat and chicken after PFGE analysis

\begin{tabular}{lcc|c}
\hline Source & Lab ID & Restriction Enzyme & Approximate restriction fragment (no.) \\
\hline Horse & H1F & Xbal & $15-16$ \\
Horse & H2VC & Xbal & $15-16$ \\
Cattle & C1VC & Xba1 & $18-19$ \\
Cattle & C2VC & Xba1 & $18-19$ \\
Cattle & C3VC & Xba1 & $18-19$ \\
Goat & G1VC & Xba1 & $15-16$ \\
Goat & G2VC & Xba1 & $15-16$ \\
Goat & G3VC & $X b a 1$ & $17-18$ \\
Goat & G5VC & $X b a 1$ & $17-18$ \\
Chicken & P1PF & $X b a 1$ & $15-16$ \\
Chicken & P3PF & $X b a 1$ & $16-17$ \\
\hline
\end{tabular}

Legend

$\mathrm{H} 1 \mathrm{~F}, \mathrm{H} 2 \mathrm{VC}=$ isolates of horse from BAUSGF

$\mathrm{C} 1 \mathrm{VC}, \mathrm{C} 2 \mathrm{VC}, \mathrm{C} 3 \mathrm{VC}=$ isolates of cattle from BAUVC

G1VC, G2VC, G2VC, G5VC = isolates of goat from BAUVC

P1PF, P3PF = isolates of chicken from BAU Poultry Farm 


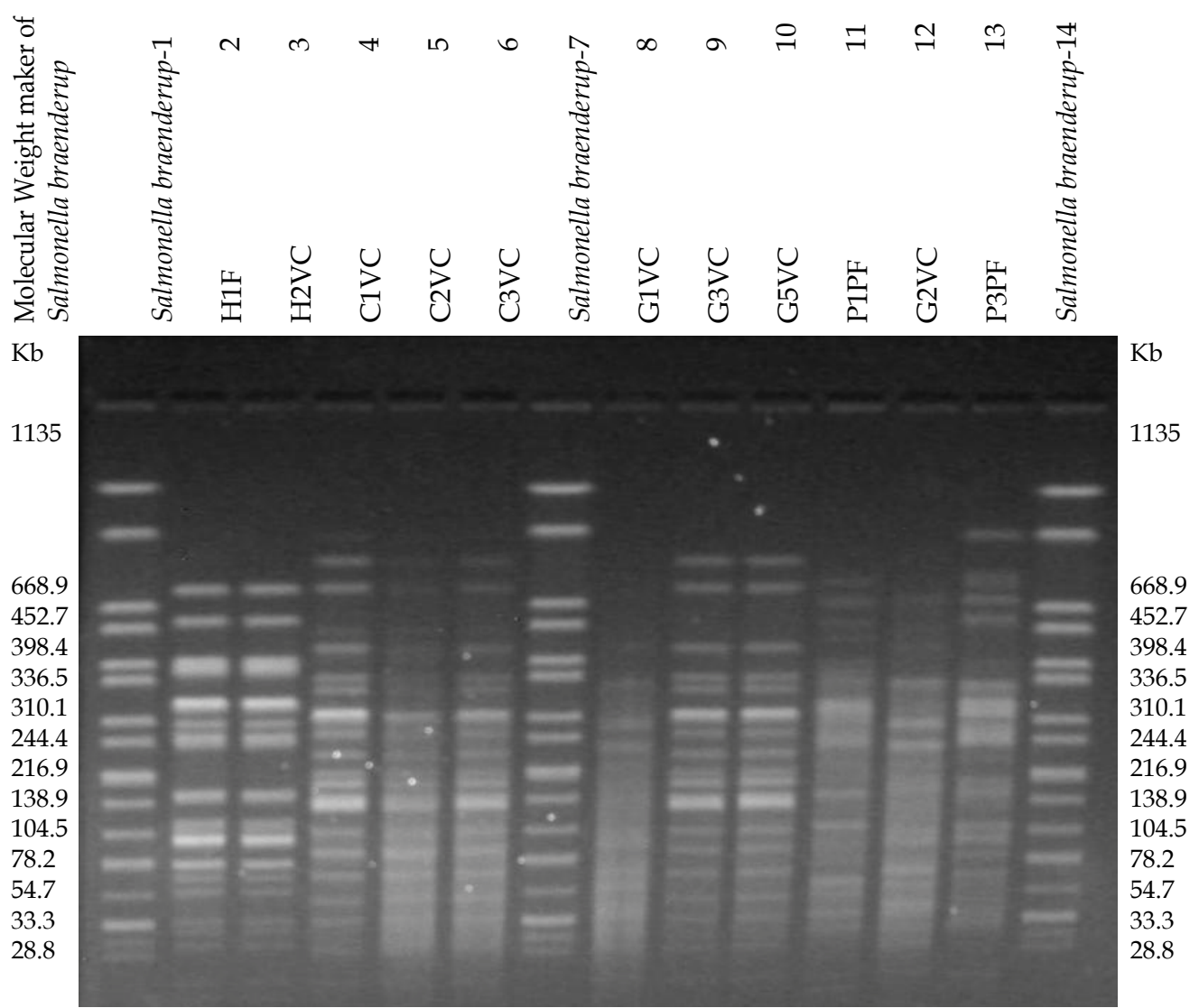

Fig. 1. PFGE pattern of representative E. coli isolated from horse, cattle, goat and chicken with Xba1

\section{Legend}

Lane 1, 7, 14 = Genomic organization of the Salmonella braenderup (Marker)

Lane 2 = Genomic organization of the isolates of horse from BAUSGF

Lane 3 = Genomic organization of the isolates of horse from BAUVC

Lane 4, Lane 5, Lane 6 = Genomic organization of the isolates of cattle from BAUVC

Lane 8, Lane 9, Lane 10, Lane 12 = Genomic organization of the isolates of goat from BAUVC

Lane 11, Lane 13 = Genomic organization of the isolates of chicken from BAU Poultry Farm

From the antibiogram study, it was revealed that among the isolates of BAUSGF, $100 \%$ were highly sensitive to ciprofloxacin, chloramphenicol and trimethoprim; $66.67 \%$ were highly sensitive and $33.33 \%$ were resistant to tetracycline; $100 \%$ were intermediately sensitive to streptomycin; $66.67 \%$ were highly sensitive and $33.33 \%$ were intermediately sensitive to gentamicin and $100 \%$ of the isolates were resistant to amoxicillin, cephalexin and cephradine. The isolates of horse from BAUVC $(100 \%)$ were highly sensitive to ciprofloxacin, chloramphenicol and cephradine; $66.67 \%$ were intermediately sensitive and $33.33 \%$ were resistant to trimethoprim; $33.33 \%$ were highly sensitive and $66.67 \%$ were intermediately sensitive to tetracycline; $66.67 \%$ were highly sensitive and $33.33 \%$ were 
intermediately sensitive to gentamicin and $100 \%$ of the isolates were resistant to amoxicillin, cephalexin and streptomycin. Among the isolates of BUP, 100\% were highly sensitive to ciprofloxacin and chloramphenicol; $50 \%$ of the isolates were highly sensitive and $50 \%$ were resistant to tetracycline; $50 \%$ were highly sensitive and $50 \%$ were resistant to streptomycin; $50 \%$ were highly sensitive and $50 \%$ were intermediately sensitive to gentamicin and $100 \%$ of the isolates were resistant to amoxicillin, cephalexin and cephradine (Table 5).

Table 5. Antibiotic sensitivity pattern of the isolated E. coli

\begin{tabular}{l|c|c|c|c|c|c|c|c|c}
\hline E. coli isolates & CIP & C & AML & CL & W & CE & TE & ST & GN \\
\hline H1F & +++ & +++ & - & - & +++ & - & +++ & ++ & +++ \\
H2F & +++ & +++ & - & - & +++ & - & +++ & ++ & +++ \\
H3F & +++ & +++ & - & - & +++ & - & - & ++ & ++ \\
H1VC & +++ & +++ & - & - & ++ & +++ & ++ & - & +++ \\
H2VC & +++ & +++ & - & - & ++ & +++ & +++ & - & +++ \\
H3VC & +++ & +++ & - & - & - & +++ & ++ & - & ++ \\
H1B & +++ & +++ & - & - & +++ & - & +++ & +++ & ++ \\
H1B & +++ & +++ & - & - & +++ & - & ++ & - & +++ \\
\hline
\end{tabular}

Legend

$\mathrm{H} 1 \mathrm{~F}, \mathrm{H} 2 \mathrm{~F}, \mathrm{H} 3 \mathrm{~F}=$ isolates of horse from BAUSGF

$\mathrm{H} 1 \mathrm{VC}, \mathrm{H} 2 \mathrm{VC}, \mathrm{H} 3 \mathrm{VC}=$ isolates of horse from BAUVC

$\mathrm{H} 1 \mathrm{~B}, \mathrm{H} 2 \mathrm{~B}=$ isolates of horse from BUP

$+++=$ highly sensitive,$++=$ intermediately sensitive

$\mathrm{CIP}=$ ciprofloxacin, $\mathrm{C}=$ chloramphenicol, $\mathrm{AML}=$ amoxicillin, $\mathrm{CL}=$ cephalexin, $\mathrm{W}=$ trimethoprim

$\mathrm{CE}=$ cephradine, $\mathrm{TE}=$ tetracycline, $\mathrm{ST}=$ streptomycin, $\mathrm{GN}=$ gentamicin

In this study, colony characteristics of E. coli observed on EMBA, MCA, SSA, BA and BGA were similar to the findings of other authors (Buxton and Fraser, 1977; Hasina, 2006 and Nazir, 2004). Differences in colony morphology manifested by the isolates may be due to loosing or acquiring some properties by the transfer of host or choice of host tissue. In Gram's staining the morphology of the isolated bacteria exhibited pink; small rod shaped Gram negative bacilli and in the hanging drops technique all the isolates revealed motility. These findings were agreed with several authors such as Buxton and Fraser (1987), Freeman (1985), Jones et al. (1987). Faecal isolates revealed a complete fermentation and all the isolates fermented dextrose, sucrose, fructose, maltose and mannitol with the production of acid and gas within $24 \mathrm{~h}-48 \mathrm{~h}$ of incubation. These results are positive as reported by Buxton and Fraser 1977 and Honda et al., 1982. The isolates also revealed positive reaction in MR test and Indole test but negative reaction in V-P test which was supported by several authors (Buxton and Fraser 1977; Honda et al., 1982). 
In PFGE method chromosomal DNA was digested with a restriction endonuclease that generates large fragments. The restriction fragments were resolved in a pattern of discrete bands. Choice of restriction enzyme is an important factor to obtain a reproducible and well discriminatory banding pattern in PFGE. Genomic organization of the strains of horse E. coli from different sources showed that they were same clonal origin but there was no clonal relationship with cattle, goat and chicken $E$. coli. These findings are supported by other studies like Bolton et al., 2007; Tenover et al., 1995. It was found that most of the E. coli isolates were resistant to amoxicillin and cephalexin. Such high prevalence of resistance may presumably be due to indiscriminate use of antibiotics at the present time, which may eventually supersede the drug sensitivity of microorganism from antibiotic saturated environment (Jawetz et al., 1984). These drug resistant bacteria can spread in the environment where man and animal acquire infection resulting in the problem of treatment of infection caused by these E. coli (Joseph et al., 1979). Almost all of the strains of horse E. coli were showed resistance pattern to amoxicillin and cephalexin. The prevalence of multi-drug resistant $E$. coli observed here appeared to be analogous to earlier predication made by many previous studies (Khan et al., 2005 and Nazir et al., 2005).

\section{CONCLUSION}

The development and use of antibiotics has been one of the most important steps towards controlling of infectious bacterial diseases in the $21^{\text {st }}$ century. However, the subsequent appearance and spread of antibiotic resistance in pathogenic organisms have made many currently available antibiotics ineffective. To successfully fight the increasing numbers of drug resistant and multi drug-resistant bacteria, extensive knowledge of the molecular mechanisms of acquiring antibiotic resistance and updated information regarding current distribution of resistance pattern is required. Prudent use of antibacterial drugs using the appropriate drug at the appropriate dosage and for the appropriate duration is one important means of reducing the selective pressure that helps resistant organisms emerge. The other vital aspect of controlling the spread of multi-drug resistant organisms is providing sufficient hygienic measures and proper care of animal for infection control in Bangladesh. Use of ciprofloxacin and chloramphenicol might be of first choice of treatment against $E$. coli infection in horses. Sufficient efforts in using antimicrobial agents wisely and strict attention to infection may prevent the emergence of resistant organisms in a great extent.

\section{REFERENCES}

Bauer, A. W., Kirdy, W. M. N., Sheris, J. C. and Truck, M. 1996. Antibiotic susceptibility testing by standardized single disc method. Am. J. Clinic. Pathol., 145: 225-230.

Bolton, D. J., Meally, A., McDowell, D. and Blair, I. S. 2007. A survey for serotyping, antibiotic resistance profiling and PFGE characterization of and the potential multiplication of restaurant Salmonella isolates. J. Appl. Microbiol., 103(5): 681-690. 
Buxton, A. and Fraser, G. 1987. Escherichina coli in Animal Microbiology. Blackwell Scientific Publications, Oxford, London, Edinburg, Melbourne. Vol. 1.

Cheesbrough. M. 1984. Medical laboratory manual for tropical countries. Ist edn. Vol. 2 Microbiology, English Language Book Society, London, 35: pp. 40-57.

Freeman, B. A. 1985. Burrows Textbook of Microbiology. $2^{\text {nd }}$ edn. In: W. B. Saunders Company London, Toronto, Mexico city, Rio de Janerio, Tokeyo. pp: 464-475.

Honda, T., Arita, M., Takela, Y. and Miwatani, T. 1982. Further evaluation of the Biken Test (Modified Eleck Test) for deletion of enterotoxigenic E. coli producing heat stable enterotoxin and application of the test to sampling of heat stable enterotoxin. J. Clinic. Microbiol., 16: 60-62.

Hung-Vu-Khac., Holoda, E., Pilipcinec, E., Blanco, M., Blanco, J. E., Mora, A., Dahbi, G., Lopez, C., Gonzalez, E. A. and Blanco, J. 2006. Serotypes, virulence genes, and PFGE profiles of Escherichia coli isolated from pigs with postweaning diarrhoea in Slovakia. BMC Vet. Res., 2(10): 150-165.

Hussain, M. M., Glass, R. J. and Khan, M. R. 1982. Antibiotic used in a rural community in Bangladesh. Int. J. Epidemiol., 11: 402-405.

Jawetz, E., Melnick, J. and Adelberg, E. A. 1984. Review of medical microbiology. 16th edn. Los Altos, California, Long Medical Publication. pp. 122-144.

Jones, T. O. 1987. Intramammary antibiotic preparation and cephalosporins resistance in Salmonella typhinurium 204c. Vet. Res., 120: 399-400.

Joseph, S. W., Daily, O. P., Hunt, W. S., Seilder, R. J., Allen, D. A. and Colwell, R. R. 1979. Aeromonas primary wound infection of a driver in polluted waters. J. Clinic. Microbiol., 10: 46-49.

Kabir, S. M. L. 2010. Avian colibacillosis and salmonellosis: a closer look at epidemiology, pathogenesis, diagnosis, control and public health concerns. Int. J. Environ. Res. Public Health, 7: 89-114.

Kaura, K. Y., Bhargava, D. N., Pruph, A. K. and Prasad, S. 1988. Pathology and isolation of multiple antibiotic resistant strain of E. coli from an out break of colibacillosis in turkey poults. Indian J. Vet. Poul. Sci., 23: 9-13.

Khan, M. F. R., Rahman, M. B., Khan, M. S. R., Nazir, K. H. M. N. H. and Rahman, M. 2005. Antibiogram and plasmid profile analysis of isolated poultry Salmonella of Bangladesh. Pakis. J. Bio. Sci., 8: 1614-1619.

Marshall, B., Petrowski, D. and Levy, S. B. 1990. Inter and Intra species spread of E. coli in a farm environment in the absence of antibiotic usage. National aca., USA, 87: 6609-6613.

Nazir, K. H. M. N. H., Rahman, M. B., Nasiruddin, K. M., Akhtar, F., Khan, M. R. F. and Islam, M. S. 2005. Antibiotic sensitivity of Escherichia coli isolated from water and its relation with plasmid profile analysis. Pakist. J. Biological Sci., 8: 1610-1613.

Tenover, F. C., Arbeit, R. D., and Goering, R. V., Murray, B. E., Persing, D. H. and Mickelsen, P. A. 1995. Interpreting chromosomal DNA restriction patterns produced by pulsed field gel electrophoresis: criteria for bacterial strain typing. J. Clinic. Microbiol., 33: 2233-2239. 